\title{
Silencing of Tumor Necrosis Factor Receptor 1 by siRNA in EC109 Cells Affects Cell Proliferation and Apoptosis
}

\author{
Ma Changhui, Ma Tianzhong, Su Zhongjing, Chen Ling, Wang Ning, Zhu Ningxia, \\ Chen Xiancai, and Chen Haibin \\ Department of Histology and Embryology, Medical College of Shantou University, Shantou, Guangdong Province 515041, China \\ Correspondence should be addressed to Chen Haibin, chenhb@stu.edu.cn
}

Received 20 February 2009; Revised 16 July 2009; Accepted 23 July 2009

Recommended by Phillip Bird

Tumor necrosis factor receptor 1 (TNFR1) is a membrane receptor able to bind TNF- $\alpha$ or TNF- $\beta$. TNFR 1 can suppress apoptosis by activating the NF- $\kappa$ B or JNK/SAPK signal transduction pathway, or it can induce apoptosis through a series of caspase cascade reactions; the particular effect may depend on the cell line. In the present study, we first showed that TNFR1 is expressed at both the gene and protein levels in the esophageal carcinoma cell line EC109. Then, by applying a specific siRNA, we silenced the expression of TNFR1; this resulted in a significant time-dependent promotion of cell proliferation and downregulation of the apoptotic rate. These results suggest that TNFR1 is strongly expressed in the EC109 cell line and that it may play an apoptosis-mediating role, which may be suppressed by highly activated NF- $\kappa$ B.

Copyright () 2009 Ma Changhui et al. This is an open access article distributed under the Creative Commons Attribution License, which permits unrestricted use, distribution, and reproduction in any medium, provided the original work is properly cited.

\section{Introduction}

Esophageal carcinoma is one of the six most common malignant tumors in the world and is associated with significant morbidity and mortality. With a high incidence in the provinces of Hebei, Henan, and Guangdong, China, esophageal carcinoma has become a serious public health threat [1]. Both genetic and environmental factors have been implicated in the development of esophageal carcinoma: however, its etiology and pathogenesis are not well understood [2-5]. At present, research into esophageal cancer is concentrated on the isolation and identification of genes and proteins involved in tumor development. Several biological markers, including cyclin D1, surviving, p53, p21, Pax, Rb, COX-2, Ras, c-Myc, Mdm2, and caveolin-1, have all been found to be aberrantly expressed in esophageal adenocarcinoma and squamous cell carcinoma [6-10]. Tumor necrosis factor (TNF) is a cytokine that is produced by activated macrophages as well as by several other cell types, including lymphocytes, fibroblasts, and hepatocytes. The effects of TNF are mediated by two distinct cell-surface receptors that are expressed simultaneously on almost all cell types: TNFR1 and TNFR2 [11]. TNFR1 seems to have a greater role than TNFR2 in TNF signaling in most cell types.
TNFR1 can suppress apoptosis by activating the NF- $\kappa \mathrm{B}$ and JNK/SAPK signal transduction pathways, and can induce apoptosis through a series of caspase cascade reactions [12, 13]. However, it is not yet clear what role TNFR1 expression may play in human esophageal carcinoma.

RNA interference (RNAi) induces sequence-specific posttranscriptional gene silencing in many eukaryotes, by using 21- and 22-nt RNA fragments that are homologous with sequences of the target gene [14]. This effect can also be observed in mammalian cells when small interfering RNAs (siRNAs) are used, and hence the method has been exploited as a powerful tool for reverse genetics in the post-genome era [15]. In the present study we detected expression of TNFR1 at the gene and protein levels in the esophageal carcinoma cell line EC109. Then, by applying a specific siRNA, we silenced the expression of TNFR1 and recorded the changes in cell proliferation and apoptosis.

\section{Materials and Methods}

2.1. Cell Culture. The human esophageal carcinoma cell line EC109 was obtained from the State Key Laboratory of Molecular Oncology, Chinese Academy of Medical Sciences, 
and grown in Dulbecco's modified Eagle's medium (DMEM, Invitrogen) supplemented with $10 \%$ fetal bovine serum. The cells were kept in culture at $37^{\circ} \mathrm{C}$ under an atmosphere of $5 \%$ carbon dioxide. To keep the cells under optimal proliferation conditions, they were passaged at $80 \%$ confluence and seeded at $20 \%$ confluence.

2.2. Transfection with siRNAs. The siRNA duplex oligonucleotides used in this study were based on the human cDNA coding for TNFR1, the efficacy of the oligonucleotides in silencing having been confirmed in a prior publication [16]. TNFR1-specific siRNA duplexes and nonsilencing control siRNA duplexes were obtained from GeneChem. The siRNA sequences applied to target the TNFR1 mRNA were $5^{\prime}$ GGAACCUACUUGUACAAUGACtt-3' (sense) and 5' -GUCAUUGUACAAGUAGGUUCCtt- $3^{\prime}$ (antisense). The siRNA sequences employed as negative controls were $5^{\prime}$-UUCUCCGAACGUGUCACGUtt-3' (sense) and 5'-ACGUGACACGUUCGGAGAAtt-3' (antisense). Twenty-four hours before transfection, $5 \times 10^{4}$ cells were seeded in a 6 -well plate. The transfection was performed using Lipofectamine 2000 transfection reagent (Invitrogen) according to the manufacturer's instructions. The EC109 cells were divided into three groups: blank control group (without transfection reagent or siRNA), negative control group (with transfection reagent and negative control-siRNA) and experimental group (with transfection reagent and TNFR1-siRNA).

2.3. RT-PCR Assays. Total RNA was extracted using RNAiso Reagent (Takara) and reverse transcription was performed using the ImProm-II Reverse Transcription System (Promega) according to the manufacturer's instructions. The primer sequences for the genes and expected product sizes were as follows: 5'-ACCAAGTGCCACAAAGGAACC-3' (forward), 5' -TACACACGGTGTTCTGTTTCTCC$3^{\prime}$ (reverse) for TNFR1 (320 bp) and 5' -ATGGATGATGATATCGCCGCG-3' (forward), 5'-CTCCATGTCGTCCCAGTTGGT-3' (reverse) for $\beta$-actin $(249 \mathrm{bp})$. The thermal cycler conditions were as follows: $94^{\circ} \mathrm{C}$ for 5 minutes, followed by 30 cycles of $94^{\circ} \mathrm{C}$ for 1 minute, $55^{\circ} \mathrm{C}$ for 45 seconds, $72^{\circ} \mathrm{C}$ for 1 minute, and then $72^{\circ} \mathrm{C}$ for 10 minutes. RT-PCR products were visualized by ethidium bromidestained agarose gels.

2.4. Western Blot Assays. The cells were washed twice with cold phosphate-buffered saline (PBS) and then membrane protein components containing TNFR1 were extracted from EC109 cells using a ProteoExtract Subcellular Proteome Extraction Kit (Merck) according to the manufacturer's instructions. The proteins were separated by sodium dodecyl sulfate-polyacrylamide gel electrophoresis (SDS-PAGE) and then transferred to a nitrocellulose membrane (Huamei). After blocking with 5\% skim milk at room temperature for 1 hour, the nitrocellulose membrane was incubated with monoclonal antibodies recognizing TNFR1 or actin ( $\mathrm{R} \&$ D) at $37^{\circ} \mathrm{C}$ for 2 hours and then with horseradish peroxidase (HRP)-conjugated secondary antibodies (Jackson) for 1 hour at room temperature. The proteins were visualized with chemiluminescence regents (Santa Cruz) and analyzed with a FluorChem 8900 system.

2.5. MTT Assay. Twenty-four hours before transfection, $5 \times$ $10^{3}$ cells were seeded in a 96-well plate. The transfection was performed using Lipofectamine 2000 transfection reagent according to the manufacturer's instructions. Four duplicate wells were set up for each group and after 8, 16, 24, and 32 hours of incubation, $10 \mu \mathrm{L}$ MTT ( $5 \mathrm{mg} / \mathrm{mL}$, Sigma) was added to each well and incubated for 4 hour. The reaction was stopped by the addition of $100 \mu \mathrm{L}$ of dimethyl sulfoxide (DMSO, Sigma). Absorbance of the samples was measured at $570 \mathrm{~nm}$ and each assay was performed in triplicate. Cell proliferation (mean absorbance \pm standard deviation) was plotted versus time.

2.6. Cell Count. For cell count analyses, cell suspensions were diluted in PBS 8, 16, 24, 32 hours after transfection. Fifty microliters of trypan blue $(0.4 \%)$ were added into $50 \mu \mathrm{L}$ of cell suspension. The number of cells without stain was counted using a hemocytometer under an inverted phase contrast microscope.

2.7. Apoptosis Detected by Flow Cytometry. Apoptosis was determined by using the Annexin V-FITC Apoptosis Detection Kit (Merck) according to the manufacturer's instructions. In brief, cells were washed twice in cold PBS and then resuspended in $1 \times$ binding buffer at a concentration of $1 \times 10^{6}$ cells $/ \mathrm{mL}$. A volume of $500 \mu \mathrm{L}$ of the solution $\left(5 \times 10^{5}\right.$ cells $)$ was transferred to another tube, and $1.25 \mu \mathrm{L}$ Annexin V-FITC were added. The cells were gently agitated and incubated in the dark for 15 minutes at room temperature, and then $500 \mu \mathrm{L}$ of cold $1 \times$ binding buffer and $10 \mu \mathrm{L}$ propidium iodide (PI) was added and the cells were analyzed with a FACScalibur flow cytometer (BD) within 1 hour.

\section{Results}

3.1. TNFR1 $m R N A$ and Protein Are Expressed in EC109. RTPCR analysis of TNFR1 mRNA in EC109 cells is shown in Figure 1(a): the $320 \mathrm{bp}$ bright band reflects high expression of TNFR1 at the genetic level. A representative Western blot analysis of TNFR1 in lysates of EC109 cells is shown in Figure 1(b): specific antibodies detected TNFR1 as a distinct band with a molecular weight of about $55 \mathrm{kDa}$.

3.2. Silencing of TNFR1 in EC109 Cells by siRNA. To confirm the silencing of TNFR1 expression in EC109 cells, RT-PCR and Western blot analysis were performed 24 hours after the transfection (Figure 2). The expression intensities of TNFR1 mRNA in the blank control group (1), the experimental group (2), and the negative control group (3) are shown (Figure 2(a)). A representative Western blot analysis of cell lysates from the blank control group (1), the experimental group (2), and the negative control group (3) is shown in Figure 2(b). 


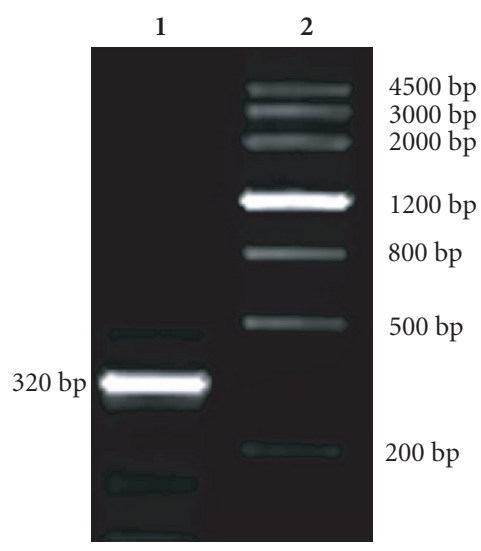

(a)

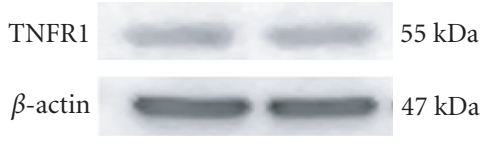

(b)

FIgURE 1: TNFR1 expression in EC109 cells. (a) Expression of TNFR1 mRNA in EC109 detected by RT-PCR. (1) TNFR1; (2) DNA marker. (b) Expression of TNFR1 at the protein level in EC109 cells detected by Western blot. Two bands with a molecular weight of $55 \mathrm{kDa}$ are expressed in EC109.

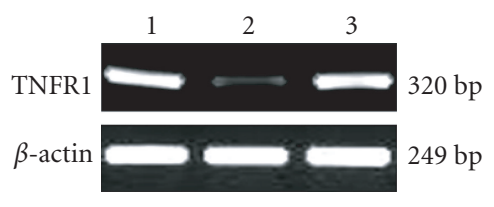

(a)

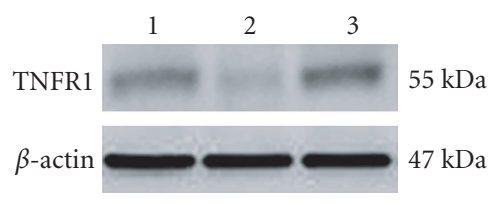

(b)

FIgURE 2: Silencing of TNFR1 in EC109 cells by siRNA. (a) The levels of TNFR1 mRNAs were analyzed by RT-PCR: (1) blank control group; (2) experimental group; (3) negative control group. (b) Expression of TNFR1 was analyzed by Western blot: (1) blank control group; (2) experimental group; (3) negative control group. Results are from one representative experiment from a total of three performed.

\begin{abstract}
3.3. Silencing of the TNFR1 Gene Increases Tumor Cell Growth. To address whether siRNA directed against TNFR1 had a promoting effect on EC109 cell growth, cell proliferation was assessed by using the MTT assay (Figure 3(a)) and by cell counting (Figure $3(\mathrm{~b})$ ). We found that treatment of EC109 cells with TNFR1-siRNA was associated with a time-dependent promotion of cell proliferation, with an accelerated cell proliferation level $(P<.05)$ observed 24 hours after transfection. No significant promotion effect was observed in cells of the blank control group or the negative control group $(P>.05)$.
\end{abstract}

3.4. Silencing of TNFR1 Gene Expression Reduces Apoptosis. Twenty-four hours after transfection, the Annexin V-FITC Apoptosis Detection Kit was employed to assess levels of apoptosis in the blank control, the negative control, and the experimental groups. The rates of apoptosis were $8.93 \pm$ $1.24 \%$ and $8.60 \pm 2.75 \%$ in the blank control group and the negative control group, respectively, with no statistically significant difference $(P>.05)$. In contrast, the rate of apoptosis in the experimental group after transfection with TNFR1-siRNA was $4.64 \pm 1.59 \%$, which is significantly lower than in the control groups $(P<.05)$ (Figure 4$)$.

\section{Discussion}

The EC109 cell line, derived from a surgically excised squamous cell carcinoma specimen, was established in 1976 by researchers in the Department of Cell and Molecular Biology, Cancer Institute, Chinese Academy of Medical Sciences. Today, the cell line is widely used for esophageal cancer-related disease research $[17,18]$. We first detected TNFR1 expression by RT-PCR and Western blot, and the results show TNFR1 has a high expression in EC109 cells compared with the immortalized esophageal epithelial cell line SHEE (data not shown).

At present, siRNA has been adapted as a functional genomics tool, although it also has the potential for therapeutic application in cancer [19-21]. Here we employed RNAi to inhibit the expression of TNFR1. We adopted TNFR1-siRNA, following Saito et al. [16], to perform the interference, and obtained data at 24 hours after transfection. Treatment of EC109 cells with TNFR1-siRNA was associated with a time-dependent promotion of cell proliferation, as measured by the MTT assay and direct cell counts, and with a significant reduction in the rate of apoptosis.

TNFR1 is known to mediate two signaling pathways: (1) TNF receptor-associated death domain (TRADD) protein 


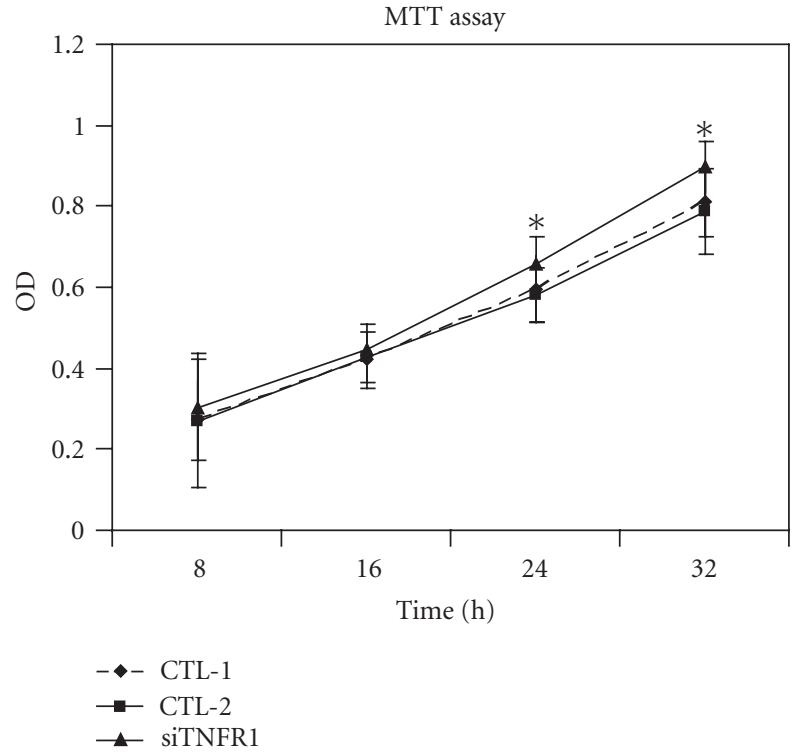

(a)

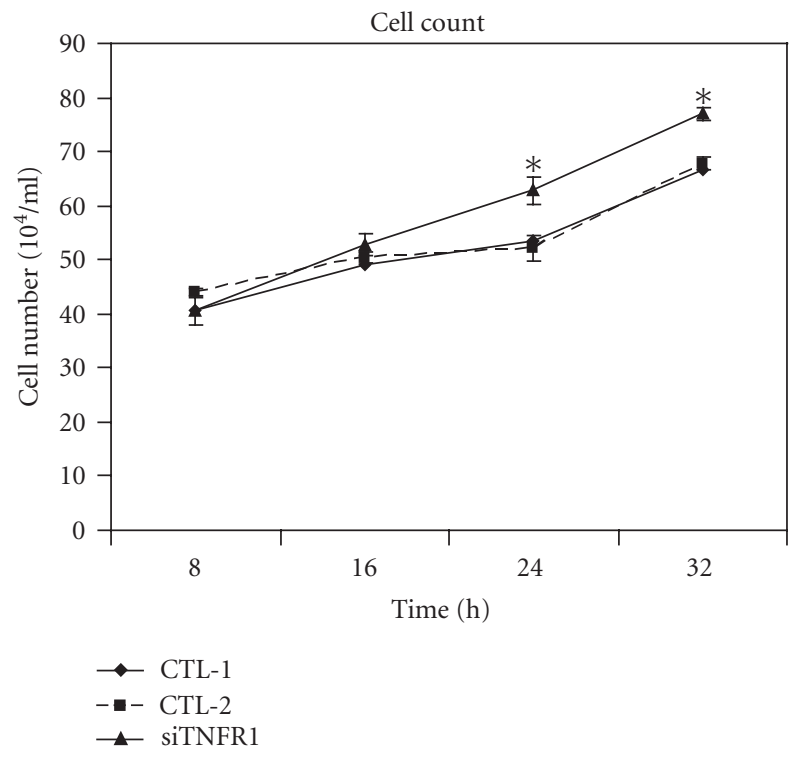

(b)

FIGURE 3: Silencing of the TNFR1 gene resulted in increased EC109 cell growth as determined by the MTT analysis (a) and cell count (b). CTL-1: blank control group; CTL-2: negative control group; Si-TNFR1: experimental group. The results show that the levels of proliferation between CTL-1 and CTL-2 were similar $(P>.05)$; the levels of proliferation between CTL- 1 and Si-TNFR1 were significantly different for the 24-hour and 32-hour time points $(P<.05)$. Data represent the mean \pm SD values of three experiments.

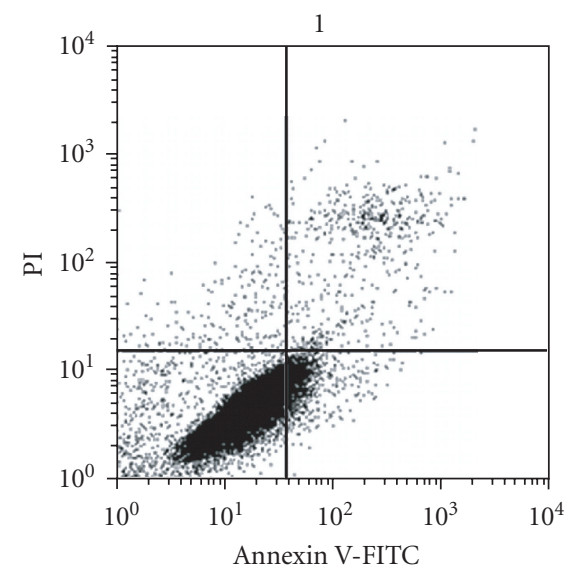

(a)

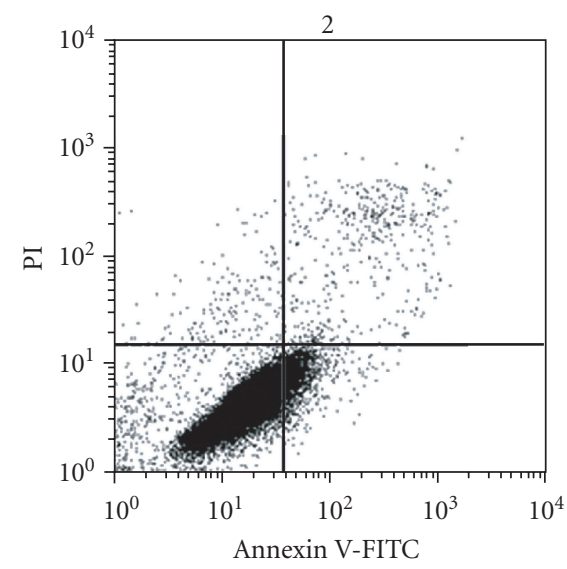

(b)

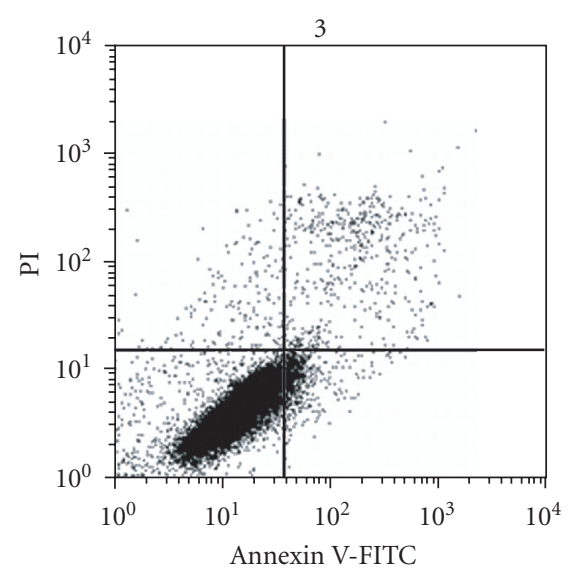

(c)

FIGURE 4: Silencing of the TNFR1 gene reduced the level of apoptosis: (1) blank control group; (2) negative control group; (3) experimental group. The results show no statistically significant difference between the rate of apoptosis in the blank control group and the negative control group. The rate of apoptosis in the experimental group was significantly lower after transfection with TNFR1-siRNA $(P<.05)$. Apoptotic cells were detected by flow cytometry. Results are from one representative experiment from a total of three performed.

binds to TNFR1 through its death domain (DD) sequence. Then, TRADD recruits the downstream signaling adaptor molecules Fas-associated death domain (FADD) and receptor interacting molecule (RIP) to constitute complex II [22]. FADD interacts with caspase- 8 or caspase- 10 precursors through a death effector domain (DED) sequence. Then another DD-containing molecule, caspase-2, and RIPK1 domain containing adaptor with death domain (RAIDD) are recruited to TNFR1 where they interact with RIP to activate
TNFR1 to initiate apoptotic signaling. (2) TNF receptorassociating factor 2 (TRAF2) is recruited to TNFR1 indirectly through a specific interaction with TRADD. TRAF2 is capable of interacting with downstream signaling molecules, resulting in the activation of NF- $\kappa \mathrm{B}, \mathrm{p} 38 \mathrm{MAPK}$, and $\mathrm{c}-\mathrm{Jun}$ $\mathrm{N}$-terminal kinase (JNK) stress kinases [23]. These latter signaling pathways all have anti-apoptotic effects.

Thus, TNFR1 plays different roles in different cells and tissues; we are interested in the role that TNFR1 plays in the 
EC109 cell line as a model of esophageal cancer. The flow cytometry results showed that TNFR1 may mediate apoptosis in EC109 cells, which is supported by the MTT results. The reduction of apoptosis rate after silencing of TNFR1 may be due to inhibition of the FADD-dependent complex II. Another report showed that NF- $\kappa \mathrm{B}$ is highly expressed in EC109, and that an activated NF- $\kappa$ B signaling pathway exists and has an effect on the survival and proliferation of these esophageal carcinoma cells [24]. The relationship between the NF- $\kappa \mathrm{B}$ signaling pathway and anti-tumor cell apoptosis has been extensively studied. Initially, Beg et al. [25] observed that the livers of nude mice lacking the NF- $\kappa \mathrm{B}$ gene showed degenerative changes because of excessive apoptosis. It was presumed that the NF- $\kappa$ B pathway was involved in suppressing apoptosis. Then a report showed that tumor cells with high NF- $\kappa$ B expression had a higher tolerance to ionizing radiation and anti-tumor drugs, and that inhibition of NF- $\kappa$ B activity could significantly increase the therapeutic sensitivity and induce apoptosis [26]. Therefore, the search for the relationship between the NF- $\kappa \mathrm{B}$ signaling pathway and tumor-cell apoptosis has been intensive and includes the study of many functional components, including CIAP1 and 2, FLIP, TRAF1 and 2, A1/BFL1, and BCL-XL. The genes encoding these proteins, all of which have anti-apoptotic effects mediated by TNF- $\alpha$ and similar positive regulatory factors, are up-regulated by activated NF- $\kappa$ B. TNFR1 in EC109 is apt to induce apoptosis and we speculate that this may be suppressed by highly-activated NF- $\kappa$ B. Higher levels of cell proliferation may reflect a reduction in cell apoptosis. It was reported that the expression rate of TNFR1 in ten different cell lines involving EC109 showed no significant differences, but that administration of new recombinant human TNF (nrhTNF) exerted significantly different effects on the different cells [27]. As nrhTNF did not inhibit the growth of five cell lines involving EC109, it was concluded that there was no correlation between the inhibitory effect of the drug and the expression of TNFR1, which supports our theory [27]. However, more research is required to confirm this.

Our results indicate that TNFR1 may mediate apoptosis in EC109 cells but the details are still unclear. Regulation of the numerous factors involved in the pathway, the relationship between TNFR1 and other relevant factors, and the specific mechanism of the pathway still need further study.

\section{Acknowledgments}

This work was supported by grants from the National Natural Science Foundation of China (No. 30370786). The first and the second authors contributed equally to this paper.

\section{References}

[1] J. M. Daly, L. H. Karnell, H. R. Menck, et al., "National cancer data base report on esophageal carcinoma," Cancer, vol. 78, no. 8, pp. 1820-1828, 1996.
[2] S. R. DeMeester and T. R. DeMeester, "Columnar mucosa and intestinal metaplasia of the esophagus: fifty years of controversy," Annals of Surgery, vol. 231, no. 3, pp. 303-321, 2000.

[3] W. N. Dinjens, "Genetic alterations in Barrett's esophagus and esophageal adenocarcinoma," Minerva Chirurgica, vol. 57, no. 6, pp. 733-752, 2002.

[4] L. B. Koppert, B. P. Wijnhoven, H. van Dekken, H. W. Tilanus, and W. N. Dinjens, "The molecular biology of esophageal adenocarcinoma," Journal of Surgical Oncology, vol. 92, no. 3, pp. 169-190, 2005.

[5] D. M. Lehrbach, M. E. Nita, and I. Cecconello, "Molecular aspects of esophageal squamous cell carcinoma carcinogenesis," Arquivos de Gastroenterologia, vol. 40, no. 4, pp. 256-261, 2003.

[6] A. Kyrgidis, J. Kountouras, C. Zavos, and D. Chatzopoulos, "New molecular concepts of Barrett's esophagus: clinical implications and biomarkers," Journal of Surgical Research, vol. 125, no. 2, pp. 189-212, 2005.

[7] D. T. McManus, A. Olaru, and S. J. Meltzer, "Biomarkers of esophageal adenocarcinoma and Barrett's esophagus," Cancer Research, vol. 64, no. 5, pp. 1561-1569, 2004.

[8] R. V. Lord, R. O'Grady, C. Sheehan, A. F. Field, and R. L. Ward, "K-ras codon 12 mutations in Barrett's oesophagus and adenocarcinomas of the oesophagus and oesophagogastric junction," Journal of Gastroenterology and Hepatology, vol. 15, no. 7, pp. 730-736, 2000.

[9] D. Güner, I. Sturm, P. Hemmati, et al., "Multigene analysis of $\mathrm{Rb}$ pathway and apoptosis control in esophageal squamous cell carcinoma identifies patients with good prognosis," International Journal of Cancer, vol. 103, no. 4, pp. 445-454, 2003.

[10] J.-K. Gerber, T. Richter, E. Kremmer, et al., "Progressive loss of PAX9 expression correlates with increasing malignancy of dysplastic and cancerous epithelium of the human oesophagus," Journal of Pathology, vol. 197, no. 3, pp. 293-297, 2002.

[11] P. Vandenabeele, W. Declerq, R. Beyaert, and W. Fiers, "Two tumour necrosis factor receptors: structure and function," Trends in Cell Biology, vol. 5, no. 10, pp. 392-399, 1995.

[12] D. J. MacEwan, "TNF ligands and receptors-a matter of life and death," British Journal of Pharmacology, vol. 135, no. 4, pp. 855-875, 2002.

[13] J. R. Muppidi, J. Tschopp, and R. M. Siegel, "Life and death decisions: secondary complexes and lipid rafts in TNF receptor family signal transduction," Immunity, vol. 21, no. 4, pp. 461465, 2004.

[14] S. M. Elbashir, W. Lendeckel, and T. Tuschl, "RNA interference is mediated by $21-$ and 22-nucleotide RNAs," Genes \& Development, vol. 15, no. 2, pp. 188-200, 2001.

[15] K. Berns, E. M. Hijmans, J. Mullenders, et al., "A large-scale RNAi screen in human cells identifies new components of the p53 pathway," Nature, vol. 428, no. 6981, pp. 431-437, 2004.

[16] F. Saito, H. Yokota, Y. Sudo, Y. Yakabe, H. Takeyama, and T. Matsunaga, "Application of RNAi inducible TNFRI knockdown cells to the analysis of TNF-alpha-induced cytotoxicity," Toxicology in Vitro, vol. 20, no. 8, pp. 1343-1353, 2006.

[17] G. Guo, S. Chen, J. Zhang, et al., "Antitumor activity of a fusion of esophageal carcinoma cells with dendritic cells derived from cord blood," Vaccine, vol. 23, no. 45, pp. 52255230, 2005.

[18] Y.-Z. Deng, P.-P. Chen, Y. Wang, et al., "Connective tissue growth factor is overexpressed in esophageal squamous cell carcinoma and promotes tumorigenicity through 
beta-catenin-T-cell factor/Lef signaling," Journal of Biological Chemistry, vol. 282, no. 50, pp. 36571-36581, 2007.

[19] A. Aigner, "Applications of RNA interference: current state and prospects for siRNA-based strategies in vivo," Applied Microbiology and Biotechnology, vol. 76, no. 1, pp. 9-21, 2007.

[20] S. Song, S. Guha, K. Liu, N. S. Buttar, and R. S. Bresalier, "COX-2 induction by unconjugated bile acids involves reactive oxygen species-mediated signalling pathways in Barrett's oesophagus and oesophageal adenocarcinoma," Gut, vol. 56, no. 11, pp. 1512-1521, 2007.

[21] E. Tanaka, Y. Hashimoto, T. Ito, et al., "The suppression of aurora-A/STK15/BTAK expression enhances chemosensitivity to docetaxel in human esophageal squamous cell carcinoma," Clinical Cancer Research, vol. 13, no. 4, pp. 1331-1340, 2007.

[22] N. S. Wilson, V. Dixit, and A. Ashkenazi, "Death receptor signal transducers: nodes of coordination in immune signaling networks," Nature Immunology, vol. 10, no. 4, pp. 348-355, 2009.

[23] N. L. Malinin, M. P. Boldin, A. V. Kovalenko, and D. Wallach, "MAP3K-related kinase involved in NF- $\kappa$ B induction by TNF, CD95 and IL-1," Nature, vol. 385, no. 6616, pp. 540-544, 1997.

[24] F. Tian, W.-D. Zang, W.-H. Hou, H.-T. Liu, and L.-X. Xue, "Nuclear factor $-\kappa \mathrm{B}$ signaling pathway constitutively activated in esophageal squamous cell carcinoma cell lines and inhibition of growth of cells by small interfering RNA," Acta Biochimica et Biophysica Sinica, vol. 38, no. 5, pp. 318-326, 2006.

[25] A. A. Beg, W. C. Sha, R. T. Bronson, S. Ghosh, and D. Baltimore, "Embryonic lethality and liver degeneration in mice lacking the RelA component of NF- $\kappa$ B," Nature, vol. 376, no. 6536, pp. 167-170, 1995.

[26] C.-Y. Wang, J. C. Cusack Jr., R. Liu, and A. S. Baldwin Jr., "Control of inducible chemoresistance: enhanced anti-tumor therapy through increased apoptosis by inhibition of NF- $\kappa \mathrm{B}$," Nature Medicine, vol. 5, no. 4, pp. 412-417, 1999.

[27] J. R. Meng, N. Zhao, Z. Yan, et al., "Expression of TNFRs in tumor cells and effect of novel rhTNF on tumor cell growth," China Journal of Cellular \& Molecular Immunology, vol. 18, no. 5, pp. 10-12, 2002. 


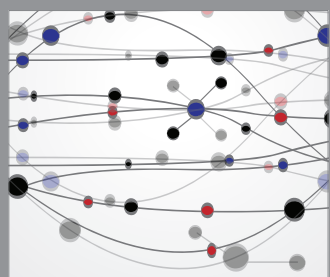

The Scientific World Journal
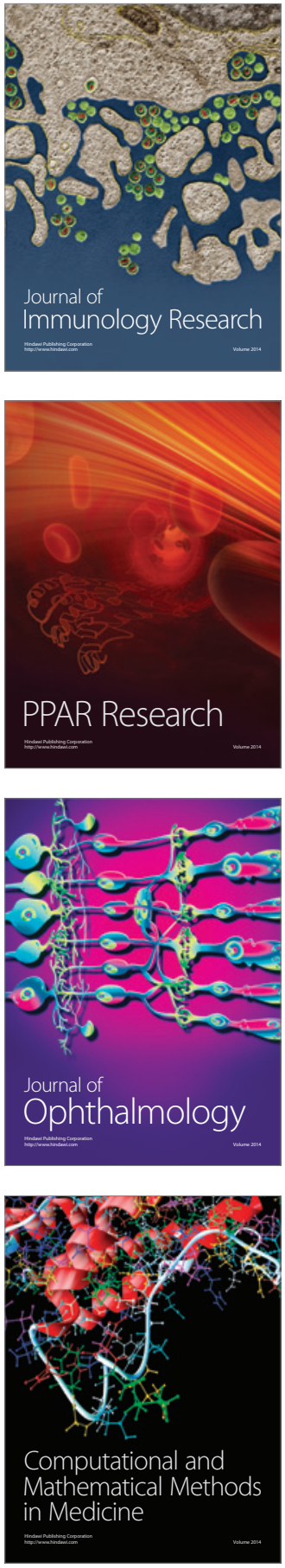

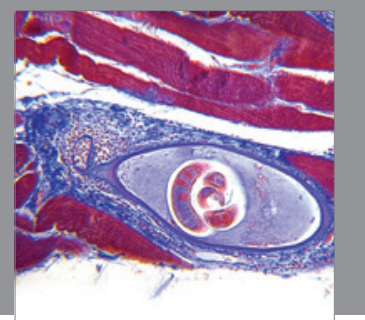

Gastroenterology

Research and Practice
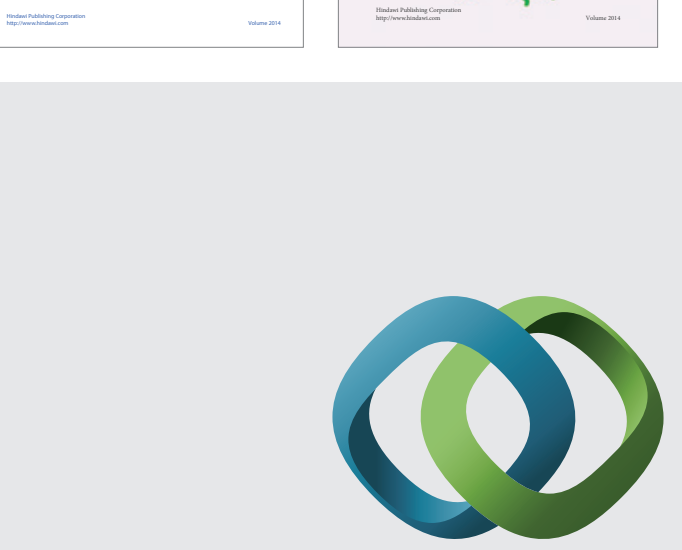

\section{Hindawi}

Submit your manuscripts at

http://www.hindawi.com
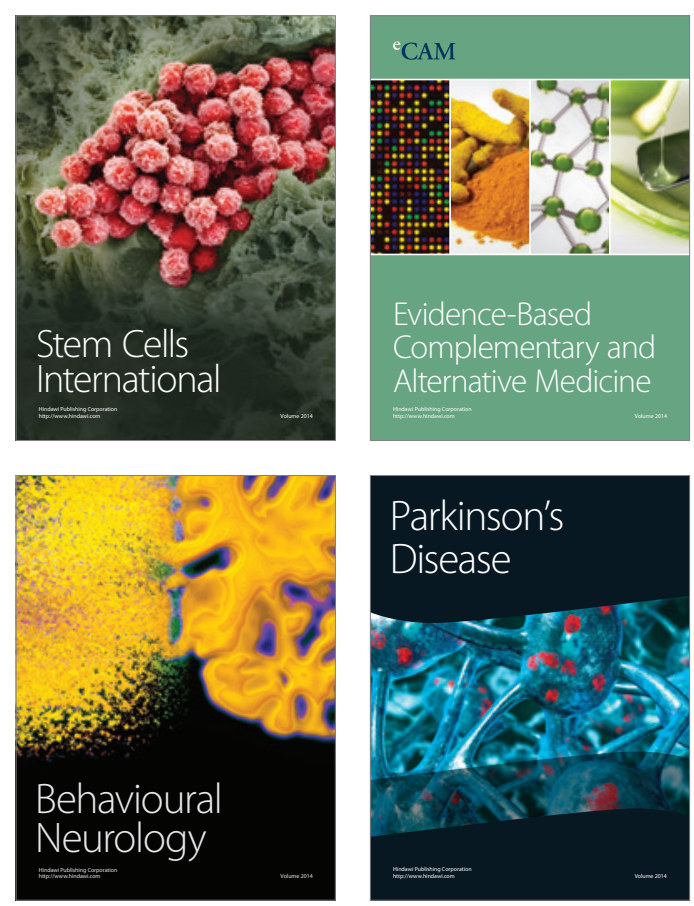

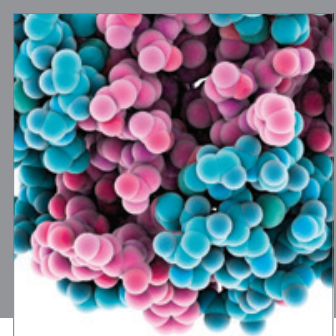

Journal of
Diabetes Research

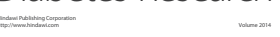

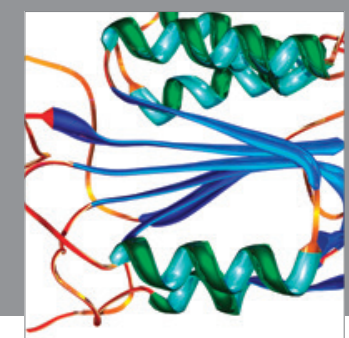

Disease Markers
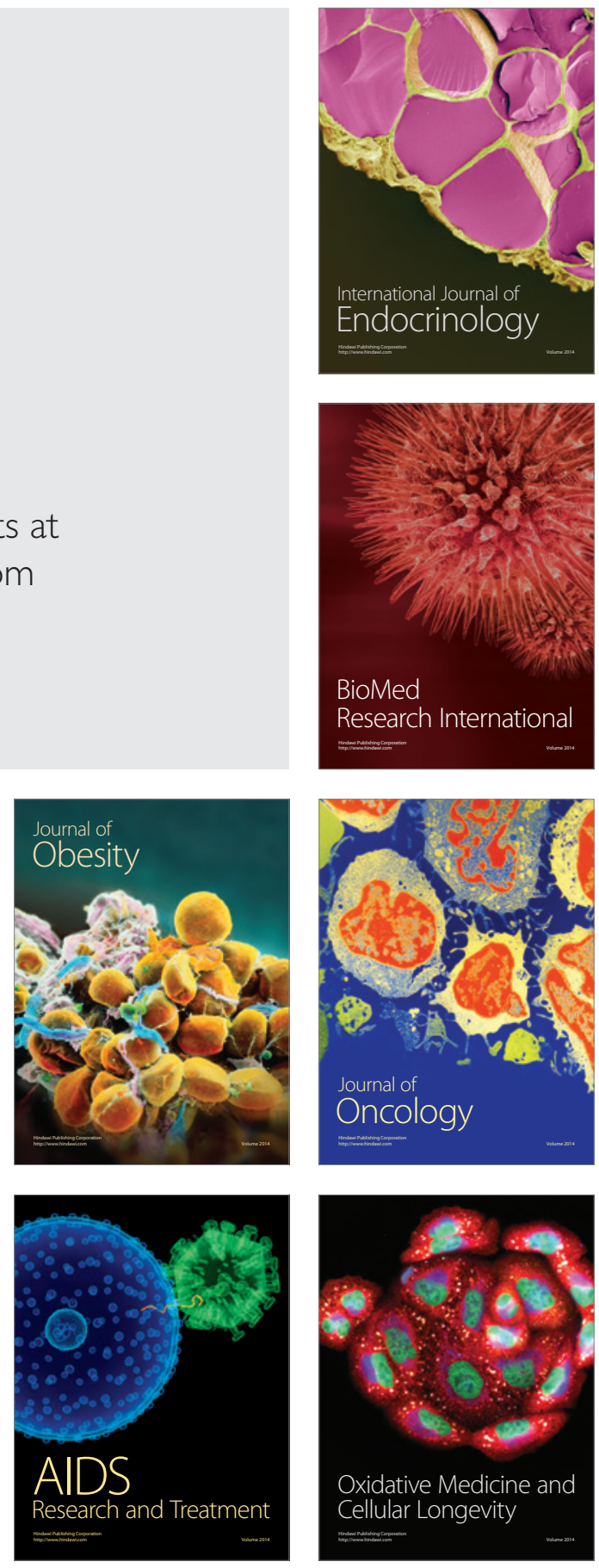